\title{
Ganglioside GM1 Binding Peptides: A Potential Adjuvant for Transcutaneous Immunization
}

\author{
Kristina K. Peachman*, Danielle M. Mclean, James C. Tong ${ }^{\S}$, Carl R. Alving and Mangala Rao \\ Department of Adjuvant and Antigen Research, Division of Retrovirology, U.S. Military HIV Research Program, Walter \\ Reed Army Institute of Research, Rockville, MD, USA
}

\begin{abstract}
Cholera toxin (CT) binds ganglioside GM1 and has been used as an adjuvant in transcutaneous immunization. To determine if the adjuvant property of CT was merely due to binding to ganglioside GM1, mice were immunized by the transcutaneous route using hen egg lysozyme (HEL) as the antigen, and either CT or synthetic peptides that bind to ganglioside GM1 as the adjuvant, and the immune responses were evaluated. Both CT and GM1 binding peptides (GM1bp) induced HEL-specific antibodies and T-cell proliferation. However, the immune responses when GM1-bp was used as the adjuvant, was much lower when compared to CT as the adjuvant. GM1-bp maintained or enhanced the co-stimulatory molecules on antigen presenting cells, in particular on JAWS II dendritic cells. Overall, the data suggests that the binding of GM1-bp to ganglioside GM1 alone can induce immune responses to the co-administered antigen.
\end{abstract}

Keywords: Cholera toxin, ganglioside GM1 binding peptides, transcutaneous immunization.

\section{INTRODUCTION}

Transcutaneous immunization (TCI), a needle-free technique, is a method of vaccination by which the antigen along with an adjuvant is applied directly on the skin [1-3]. The antigen and the adjuvant travel through hydrated skin and induce potent cellular, humoral and mucosal immune responses against a wide range of protein and peptide antigens including DNA and influenza antigens [4-10].

The most effective and widely used adjuvants for TCI have been the ADP-ribosylating bacterial exotoxins, including heat-labile enterotoxin (LT) and cholera toxin (CT) [2]. CT and LT are each composed of 5 identical B subunits that bind to the receptor ganglioside GM1 on the cell surface. The B subunits are non-covalently linked to a single A subunit consisting of two domains A1 and A2 [11-12]. While the pathways by which CT and LT act as adjuvants have not been fully elucidated, two attributes of these complex toxins are central to this function, enzymatic ADPribosyltransferase activity and high-affinity ganglioside GM1 binding to cell membranes [13]. The A subunit exhibits ADP-ribosyltransferase activity while the pentameric B subunit is responsible for binding the toxins through the receptor. Through ADP ribosylation of $\mathrm{G}$ proteins and activation of adenylate cyclase, the enzymatic A1 subunit initiates a cascade of events that promotes an outflow of intracellular fluids (enterotoxicity) and stimulates a number of other less well-understood cell signaling pathways. These signaling pathways potentiate immune responses to

\footnotetext{
*Address correspondence to this author at the Department of Adjuvant and Antigen Research, Division of Retrovirology, 1600 East Gude Drive, Rockville, MD 20850 USA; Phone: (301) 251-5076; Fax: (301) 424-3120; E-mail: kpeachman@hivresearch.org

${ }^{\S}$ Current address: Telemedicine \& Advanced Technology Research Center, Ft. Detrick, Fredrick, MD, USA
}

co-administered antigens [11]. Dissociation of adjuvant and enterotoxic effects by introduction of mutations in or around the A1 active site have been somewhat successful, although disagreement remains about the contribution of residual enzymatic activity in the adjuvant properties of these mutant toxins [14-16].

The binding of B subunit of CT and LT to GM1 ganglioside is essential to their adjuvant property and is important in directing and properly presenting the molecule to antigen presenting cells [17-19]. Toxin binding to GM1 also triggers events that result in efficient antigen uptake and activation of cell signals that improve antigen presentation [20]. The non-toxic B subunit pentamer of LT or CT has been coupled to antigen as well as co-administered with soluble protein antigen by the intranasal route and shown to induce IgA and IgG-mediated protective mucosal immunity [21-24].

Despite their success as adjuvants in animal studies, the utility of LT and CT in humans has been limited because of their inherent toxicity when administered by the oral or intranasal routes and poses a challenge to their usage [25, 26]. Clinical trials using LT in the transcutaneous immunization platform are ongoing and have to date induced potent immune responses to vaccines and proven to be safe with no toxic side effects $[27,28]$. Research to elucidate the molecular basis of adjuvanticity and toxicity with a view to exploit the successful adjuvant properties of the toxin have been undertaken.

Using a phage-displayed pentadecapeptide library, Matsubara et al. identified ganglioside GM1 binding peptides (GM1-bp). These small 15mer peptides bound with high affinity to a GM1 monolayer [29]. Remarkably, none of the three peptides displayed any similarity to the GM1 binding site of CTB or LTB, yet all three inhibited the binding of CTB to GM1 monolayers. In addition, Montaner et al. [30] described 45 additional GM1-bp. They utilized 
two of the peptides for intranasal immunization with influenza proteins and demonstrated that both mucosal as well as systemic antibody responses were generated [30]. These GM1-bp could prove to be safe and potent adjuvants and may also provide a useful and unique tool to define the specific contribution of GM1 binding to the generation of immune responses.

In this study, we demonstrate that when the antigen HEL along with GM1-bp as the adjuvant is applied on the backs of mice by the transcutaneous route, immune responses are induced to the antigen as well as the adjuvant. However, the responses with GM1-bp were much weaker compared to when CT was used as the adjuvant. These results suggest that binding of ganglioside GM1 alone is sufficient to induce an immune response.

\section{MATERIALS AND LABORATORY PROCEDURES}

\section{Mice and Reagents}

$\mathrm{C} 57 \mathrm{BL} / 6$ and $\mathrm{BALB} / \mathrm{c}$ mice were purchased from Jackson Laboratory (Bar Harbor, ME). Hen egg lysozyme (HEL) was purchased from Sigma-Aldrich (St. Louis, MO). RPMI-1640, fetal bovine serum, L-glutamine, penicillin, streptomycin, and phosphate-buffered saline (PBS) were obtained from Gibco-BRL Life Technologies part of Invitrogen Corp. (Rockville, MD). Three ganglioside GM1 binding peptides (GM1-bp) GA, DP, and VP [29] were commercially purchased from The American Peptide Company. The respective sequences for the three GM1-bps are as follows: GWWYKGRARPVSAVA; DFRRLPGAF WQLRQ; and VWRLLAPPFSNRLLP. Anti-CD80, antiCD86, anti-H-2K ${ }^{\mathrm{b}}$, anti-H-2K ${ }^{\mathrm{d}}$, anti-IA ${ }^{\mathrm{b}}$, anti-IA ${ }^{\mathrm{d}}$, anti-IL-4 (clone BVD4-11), biotinylated anti-IFN $\gamma$ (clone XMG 1.2) and biotinylated anti-IL-4 (clone BVD6-24G2) were purchased from BD Biosciences PharMingen (San Diego, CA). Cholera toxin (CT) was purchased from List Biological Laboratories, Inc. (Campbell, CA). Immunopure goat F(ab') anti-mouse $\operatorname{IgG}(\mathrm{H} \& \mathrm{~L})$ was purchased from Pierce Biotechnology Inc. (Rockford, IL). Ninety six-well Ubottom Immulon-2 polystyrene plates were purchased from Dynatech Laboratories (Chantilly, VA). Phosphatase-labeled goat anti-mouse IgG, substrate p-nitrophenyl phosphate and BCIP/NBT were bought from Kirkegaard \& Perry Laboratories (Gaithersburg, MD). Multi-Screen-IP sterile plates were purchased from Millipore (Bedford, MA). AntiIFN $\gamma$ (clone RMGG-1) was from BioSource, International, Inc., (Camarillo, CA). Avidin-conjugated alkaline phosphatase was purchased from Vector Laboratories (Burlingham, CA). Murine gamma-interferon was purchased from R\&D Systems (Minneapolis, MN).

\section{Mouse Immunizations}

Six to eight-week-old-female BALB/c mice were maintained in a specific-pathogen-free facility. Each group of five mice was housed in an individual cage and given water and food ad libitum. This study was conducted in compliance with the Animal Welfare Act and adhered to the principles enunciated in the Guide for the Care and Use of Laboratory Animals. The investigators used facilities fully accredited by the Association for Assessment and Accreditation of Laboratory Animal Care, International. All animal experimentation was approved by the WRAIR
Animal Safety Committee. The backs of the mice were shaved one day prior to immunization with a Wahl razor. The mice were immunized via transcutaneous immunization (TCI) $[31,32]$. The backs of the mice were hydrated with water before the addition of the antigens in a total volume of 50-110 $\mu \mathrm{L}$. The groups (Table 1) included Group 1: naive (no treatment); Group 2: $50 \mu \mathrm{g} \mathrm{CT}$; Group 3: [100 $\mu \mathrm{g}$ of all three GM1-bp (33.3 $\mu \mathrm{g} /$ peptide)]; Group 4: (100 $\mu \mathrm{g}$ HEL + $50 \mu \mathrm{g}$ CT); Group 5: [100 $\mu \mathrm{g}$ HEL + $100 \mu \mathrm{g}$ GM1-bp (33.3 $\mu \mathrm{g} /$ peptide)]; Group 6: [100 $\mu \mathrm{g}$ HEL + $50 \mu \mathrm{g}$ GM1-bp (16.67 $\mu \mathrm{g} /$ peptide)]. Mice were immunized at weeks 0,3 , and 6. Groups 3, 5, and 6 were boosted again at 9 weeks. Animals were bled at $0,2,4,8,12,14$ and 16 weeks. Spleens and inguinal lymph nodes were taken at week 16.

Table 1. BALB/c Mice (5 Mice/Group) were Immunized by the Transcutaneous Route with the Antigen and Adjuvant Shown

\begin{tabular}{|l|c|c|}
\hline \multicolumn{1}{|c|}{ Group } & Antigen & Adjuvant \\
\hline \hline 1. Naive & None & None \\
\hline 2. Cholera Toxin $(\mathrm{CT})$ & None & CT $(50 \mu \mathrm{g})$ \\
\hline 3. GM1-bp & None & $\begin{array}{c}\text { Total GM1-bp }(100 \mu \mathrm{g}) \\
(33.3 \mu \mathrm{g} / \mathrm{peptide})\end{array}$ \\
\hline 4. HEL + CT & HEL $(100 \mu \mathrm{g})$ & CT $(50 \mu \mathrm{g})$ \\
\hline 5. HEL + GM1-bp & HEL $(100 \mu \mathrm{g})$ & $\begin{array}{c}\text { Total GM1-bp }(100 \mu \mathrm{g}) \\
(33.3 \mu \mathrm{g} / \mathrm{peptide})\end{array}$ \\
\hline 6. HEL + GM1-bp & HEL $(100 \mu \mathrm{g})$ & $\begin{array}{c}\text { Total GM1-bp }(50 \mu \mathrm{g}) \\
(16.67 \mu \mathrm{g} / \mathrm{peptide})\end{array}$ \\
\hline
\end{tabular}

\section{ELISA}

Solid-phase enzyme-linked immunosorbent assays (ELISA) were performed to measure the HEL- and CTspecific IgG antibodies. HEL and CT protein were used as the capture antigens as described previously [33]. Immulon-2 96-well U-bottom polystyrene plate were coated with HEL or CT $(2 \mu \mathrm{g} / \mathrm{ml}, 0.1 \mathrm{ml} /$ well $)$ in antigen diluent $[4 \mu \mathrm{g} / \mathrm{ml}$ boiled casein in phosphate buffered saline (PBS)] overnight at $4-6^{\circ} \mathrm{C}$ and then blocked with $0.5 \%$ casein in $\mathrm{PBS}$ containing 1\% Tween 20 (PBS-casein-Tween). Individual mouse serum diluted in PBS-casein-Tween were added to the plates in triplicate wells and incubated overnight at 4$6^{\circ} \mathrm{C}$. After washing with $0.05 \%$ Tween 20 in PBS (PBSTween), the plates were incubated with phosphatase-labeled goat anti-mouse IgG for $2 \mathrm{~h}$ at room temperature and then washed again with PBS-Tween. Substrate (p-nitrophenyl phosphate) was added and the plates were incubated in the dark for $30 \mathrm{~min}$ (CT) or $1 \mathrm{hr}$ (HEL). Absorbance was read at $405 \mathrm{~nm}$ with an Uvmax plate reader (Molecular Devices, Sunnyvale, CA). The data are expressed as endpoint titers defined as the highest dilution that yielded an optical density reading greater than or equal to twice that of the background values.

\section{Proliferation}

Spleen and lymph nodes obtained from naive and immunized mice were cultured in complete RPMI 1640 media containing $0.5 \%$ normal mouse serum. Cultures were set up in 96-well plates in triplicate in $0.2 \mathrm{ml}$ volumes at a concentration of $5 \times 10^{5}$ cells $/ \mathrm{ml}$ for spleen cells or at a 
concentration of $2.5 \times 10^{5}$ cells $/ \mathrm{ml}$ for lymph node cells in the presence or absence of HEL or GM1-bp (1, 3, 10, and 30 $\mu \mathrm{g} / \mathrm{ml}$, respectively) for 5 days. During the last $16 \mathrm{~h}$ of the culture period, cells were pulsed with $1 \mu \mathrm{Ci}$ of ${ }^{3}[\mathrm{H}]$ thymidine per well [34]. Cells were then harvested onto glass fiber filters. The data are expressed as stimulation indices $\left[{ }^{3}(\mathrm{H})\right.$ thymidine incorporation in the presence of antigen divided by the same in the absence of antigen] plus or minus standard error.

\section{ELISPOT}

Spleen and lymph node cells secreting IFN- $\gamma$ and IL-4 were analyzed by ELISPOT as previously described [34]. Briefly, single cell suspensions were prepared from the spleen and lymph nodes of naive and immunized mice (3 mice/group). Spleen cells $\left(1 \times 10^{6}\right.$ cells/well $)$ and lymph node cells $\left(2.5 \times 10^{5}\right.$ cells/well $)$ were plated on anti-IFN $\gamma$ and anti-IL-4 coated 96-well nitrocellulose-backed MultiScreenIP sterile plates. Cells were incubated with or without HEL $(30 \mu \mathrm{g} / \mathrm{ml})$ for $18 \mathrm{~h}$ at $37^{\circ} \mathrm{C}$ in a humidified $\mathrm{CO}_{2}$ incubator. Plates were washed, overlaid with $0.125 \mu \mathrm{g} / \mathrm{ml}$ of either biotinylated anti-IFN- $\gamma$ or biotinylated anti-IL-4, and incubated at RT for $2 \mathrm{~h}$. The plates were then washed and incubated with 1:1000 dilution of avidin-conjugated alkaline phosphatase for $2 \mathrm{~h}$ at RT. The plates were washed and bound IFN $\gamma$ or IL-4 was detected by the addition of $\mathrm{BCIP} / \mathrm{NBT}$. The plates were washed with water and the individual spots were visualized and counted the next day using a stereo-binocular microscope. The average number of spots/number of cells plated was calculated.

\section{Preparation of Antigen Presenting Cells (APCs)}

Bone marrow-derived macrophages (BMs) were cultured from the marrow of $\mathrm{C} 57 \mathrm{BL} / 6$ mice $\left(\mathrm{H}-2^{\mathrm{b}}\right)$ or BALB/c mice $\left(\mathrm{H}-2^{\mathrm{d}}\right)$. Cells were grown on either acid-washed circular glass coverslips or in $100 \mathrm{~mm}$ tissue culture plates as previously described [35]. On day 9, macrophages were supplemented with $10 \mathrm{U} / \mathrm{ml}$ of murine interferon gamma (IFN- $\gamma$ ) and used as APCs the next day.

\section{Surface Marker Expression}

On day 9, primary bone marrow derived-murine macrophages and JAWS II dendritic cells were treated with or without IFN- $\gamma(10$ units $/ \mathrm{ml})$ and with or without $1 \mu \mathrm{g} / \mathrm{ml}$ of CT or $1 \mu \mathrm{g} / \mathrm{ml}$ of GM1-bp $(0.333 \mu \mathrm{g} / \mathrm{ml}$ per peptide). Cells were incubated overnight at $37^{\circ} \mathrm{C}$. The following day, cells were scrapped and placed in 96-well U-bottom plates ( $\sim 500,000$ cells /well). Cells were washed in PBS containing $\mathrm{Ca}^{2+}$ and $\mathrm{Mg}^{2+}$. Non-specific binding was blocked with 1:100 goat serum in PBS for $5 \mathrm{~min}$ on ice. Cells were then incubated with $4 \mu \mathrm{g} / \mathrm{ml}$ anti-H-2 $\mathrm{K}^{\mathrm{d}}$, anti-IA ${ }^{\mathrm{d}}$ for $\mathrm{BALB} / \mathrm{c}$ mice or anti-H-2 $\mathrm{K}^{\mathrm{b}}$ and anti-IA ${ }^{\mathrm{b}}$ for $\mathrm{C} 57 \mathrm{BL} / 6$ mice or antiCD80 (B7-1) or anti-CD86 (B7-2) for $1 \mathrm{~h}$ at $4^{\circ} \mathrm{C}$. Cells were washed, followed by the addition of $4 \mu \mathrm{g} /$ well of purified FITC-conjugated goat $\mathrm{F}\left(\mathrm{ab}^{\prime}\right)_{2}$ anti-mouse IgG. Cells were incubated at $4^{\circ} \mathrm{C}$ for $1 \mathrm{~h}$, washed in PBS and then analyzed on a FACS Calibur flow cytometer (Becton Dickinson, San Jose, CA). The results were analyzed using CellQuest (Becton Dickinson, San Jose, CA) software.

\section{RESULTS}

\section{HEL and CT Specific Antibody Responses}

Mice were immunized by the transcutaneous route with HEL as the antigen and either CT or GM1-bp as the adjuvant. Individual serum samples were analyzed for the presence of HEL and CT-specific antibodies at weeks 4, 8, 12 , and 16 by ELISA.

As shown in Fig. (1A), mice immunized with HEL and CT (Group 4) showed consistently high HEL-specific IgG titers from weeks 4 through 16 with an endpoint titer of 153,600 at week 16. HEL-specific IgG antibodies were also induced in mice immunized with GM1-bp (Groups 5 and 6) as the adjuvant (Fig. 1B). However, the titers were significantly lower in Group $5(\mathrm{p} \leq 0.04)$ and the response was delayed by 4 weeks compared to Group 4 . Only one out of 5 mice induced HEL-specific IgG antibodies when immunized with the lower dose of GM1-bp (Fig. 1B, open bars), whereas four out of the five mice induced HEL-specific IgG antibodies when immunized with the higher dose of GM1-bp

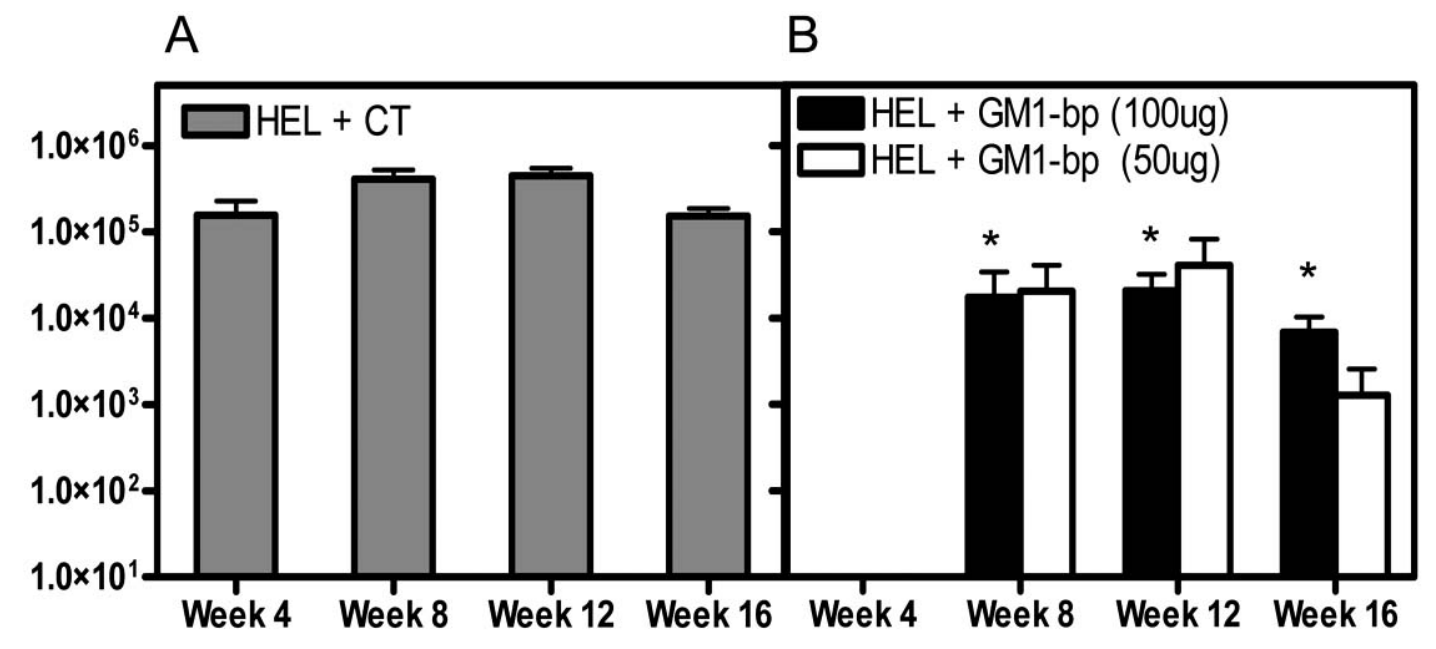

Fig. (1). GM1-bp serve as an adjuvant for the induction of HEL-specific IgG antibodies. (A) HEL-specific IgG ELISA endpoint titers (gray bars) for Group $4(100 \mu \mathrm{g} \mathrm{HEL}+50 \mu \mathrm{g} \mathrm{CT})$ at weeks 4, 8, 12 and 16 post-immunization. (B) HEL-specific IgG ELISA endpoint titers for Group $5(100 \mu \mathrm{g} \mathrm{HEL}+100 \mu \mathrm{g}$ GM1-bp) [black bars] and Group $6(100 \mu \mathrm{g}$ HEL $+50 \mu \mathrm{g}$ GM1-bp) [white bars]. Each bar represents the mean end point titers of 5 mice \pm SEM of each group. *represents statistically significant difference compared to Group 4 ( $p \leq 0.04$ ). 
Table 2. Individual Serum Samples from Groups 2 (CT Alone) and 4 (HEL + CT) were Analyzed for CT-Specific IgG Antibodies. Values are Depicted as the Mean Endpoint Titers of 5 Mice \pm the SEM.

\begin{tabular}{|c|c|c|c|c|}
\hline & Week 4 & Week 8 & Week 12 & Week 16 \\
\hline \hline $\mathrm{CT}$ & $225,280 \pm 50,167$ & $>819,200$ & $>620,838$ & $158,720 \pm 70,984$ \\
\hline $\mathrm{HEL} \pm \mathrm{CT}$ & $245,760 \pm 69,453$ & $>819,200$ & $>819,200$ & $358,400 \pm 160,286$ \\
\hline
\end{tabular}

(Fig. 1B, solid bars). HEL-specific endpoint titers were below levels of detection in all groups of mice at week 0 (Fig. 1A; titers $<100$ ) and in Group 5 and 6 mice at week 4 (Fig. 1B; titers $<100$ ).

CT-specific IgG antibodies for Group 2 (CT $50 \mu \mathrm{g}$ ) and Group 4 (HEL + CT) are shown in Table 2. Both groups had extremely high titers $(>819,200$ at week 8$)$. Although, at week 16, CT-specific IgG antibody endpoint titers for Group 2 were 2-fold lower than Group 4, the titers were not statistically significant $(p=0.24)$. The above results demonstrate that GM1bp do serve as an adjuvant to induce HEL-specific IgG antibodies when applied on the skin along with HEL as the antigen.

\section{Effect of GM1-bp on T-Cell Proliferation}

At week 16, spleens and draining lymph nodes from naive and immunized mice were pooled and single cell suspensions were made and tested for cellular immune responses. Single cell suspensions were incubated with either

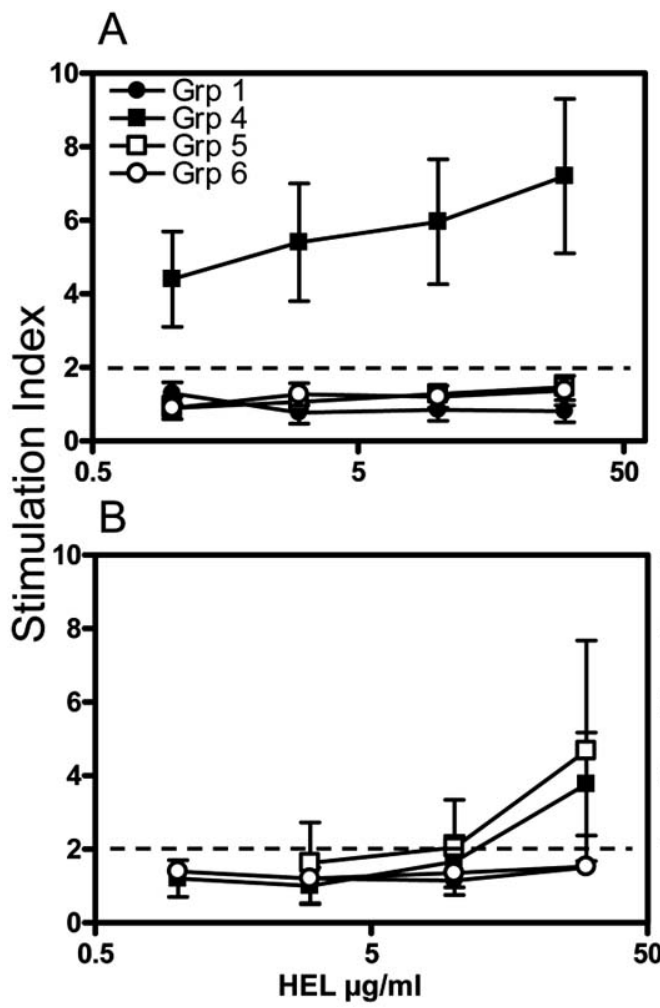

Fig. (2). HEL and GM1-bp-specific proliferation in immunized mice. Spleen (A and C) and lymph node (B and D) cells were cultured with various concentrations of HEL or GM1-bp before the addition of ${ }^{3} \mathrm{H}$-thymidine for $16 \mathrm{~h}$. The following groups are included in the proliferation assays: Group 1 (naive) [closed circle], Group 4 (HEL + CT) [closed square], Group 5 (HEL 100 $\mu \mathrm{g}+\mathrm{GM} 1-\mathrm{U} 100 \mu \mathrm{g})$ [open square], and Group 6 (HEL $100 \mu \mathrm{g}+$ GM1-U $50 \mu \mathrm{g}$ ) [open circle]. (A) HEL-specific proliferation in spleen cells. Cells only from Group 4 $(\mathrm{HEL}+\mathrm{CT})$ proliferated in response to HEL stimulation. (B) HEL-specific proliferation in lymph node cells. (C) GM1-bp-specific proliferation in spleen cells. (D) GM1-bp-specific proliferation in lymph node cells. Data are expressed as the stimulation index \pm S.E., assuming that the proliferation obtained in the absence of antigen is 1. Data shown are representative of 2 separate experiments. 
concentration tested $(30 \mu \mathrm{g} / \mathrm{ml})$. The stimulation indices were 3.8 and 4.7, respectively. Immunization with HEL and $100 \mu \mathrm{g}$ of GM1-bp (Group 5, open squares) induced a very strong in vitro recall response to GM1-bp with stimulation indices of 11.5, 17.1 and 27.8, respectively (Fig. 2D).

\section{IL-4 and IFN- $\gamma$ Secretion}

To determine if $\mathrm{T}$ cells were making IFN- $\gamma$, naive and immune spleen and lymph node cells were tested by ELISPOT assay for the production of IL-4 and IFN- $\gamma$. As shown in Fig. (3A , B), in vitro stimulation of spleen and lymph node cells obtained from mice immunized with HEL and CT (Group 4) resulted respectively in a 7-fold and a 12.5-fold increase in IFN $\gamma$ production over spontaneous background levels. Black bars indicate wells incubated with HEL, while white bars indicate cells incubated with media alone. Immunization with HEL and high dose GM1-bp (Group 5) induced a 3.2-fold increase in IFN $\gamma$ producing cells in the spleen over background levels (Fig. 3A). However, a similar response was not observed with the lymph node cells (Fig. 3B, Group 5). IL-4 was produced from the spleen (2-fold) and lymph node cells (14.5-fold) of mice immunized with HEL and CT (Fig. 3C, D, respectively). A very slight IL-4 response was observed with both the spleen and lymph node cells with the high dose GM1-bp (Group 5).

\section{Effect of GM1-bp on the Expression of Cell Surface Markers}

To determine if the binding of cell surface ganglioside GM1 with its ligand influences the expression of immunological surface markers, cells were incubated with CT or GM1-bp and then analyzed for the levels of MHC

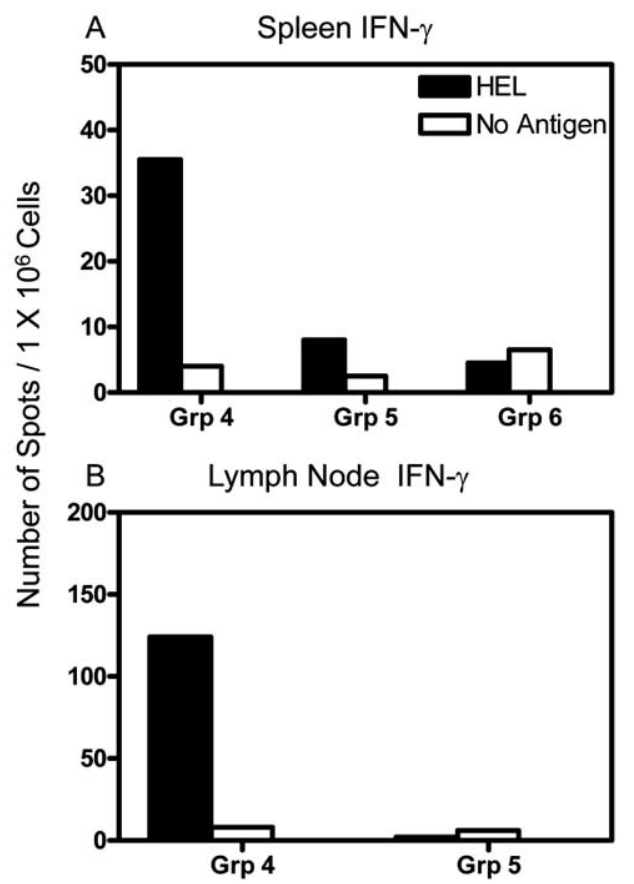

class I molecules, class II molecules, and the co-stimulatory molecules CD 80 and CD 86 (B7.1/B7.2). Unstimulated or IFN $\gamma$ stimulated murine bone marrow-derived macrophages were cultured for $24 \mathrm{~h}$ with media or with $1 \mu \mathrm{g}$ each of CT or GM1-bp and then analyzed by flow cytometry (Fig. 4). Both CT and GM1-bp caused a significant decrease $(\mathrm{p}=0.025$ and $p=0.004$, respectively) in the surface expression of MHC class I molecules compared to cells incubated with media alone (Fig. 4A). The levels of MHC class II molecules were unaffected by the treatment (Fig. 4B). CT caused a significant increase $(\mathrm{p}=0.035)$ in the surface expression of both co-stimulatory molecules, CD80 (Fig. 4C) and CD86 (Fig. 4D) compared to untreated cells, while GM1-bp did not significantly affect their surface expression.

It is well known that IFN- $\gamma$ causes an increase in the antigen processing and presentation machinery [reviewed 36]. Our results also demonstrate that IFN- $\gamma$ caused an increase in the surface expression of MHC class I, class II, CD80 and CD86 molecules (Fig. 4). Incubation of IFN- $\gamma$ treated cells with GM1-bp did not significantly affect the levels of any of the surface molecules tested (Fig. 4). However, unlike GM1-bp, incubation of IFN- $\gamma$ treated cells with CT caused a significant decrease $(\mathrm{p}=0.01)$ in $\mathrm{MHC}$ class II molecules (Fig. 4B) and an enhancement $(p=0.025)$ in the expression of CD86 molecules (Fig. 4D) without affecting MHC class I (Fig. 4A) and CD80 molecules (Fig. 4C).

In addition to macrophages, dendritic cells are important professional antigen presenting cells and are the target cells in TCI. TCI induces the uptake of antigens by skin dendritic cells or Langerhans cells and stimulates these cells to migrate from the epidermis to lymph nodes. To investigate the role of GM1-bp on dendritic cell surface markers, we

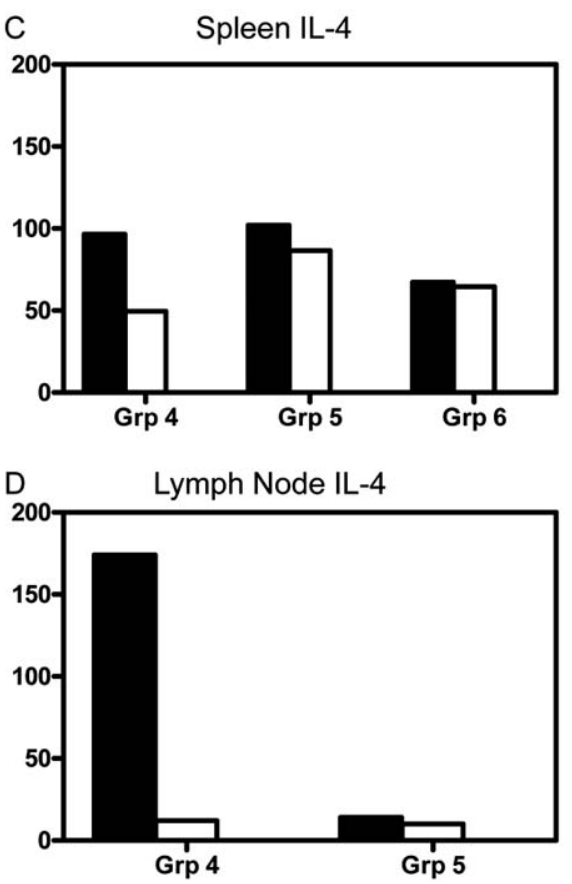

Fig. (3). HEL-specific IFN- $\gamma$ and IL-4 cytokine production as measured by ELISPOT. Spleen cells (A, C) or lymph node cells (B, D) were stimulated with HEL (black bars) or media (white bars) overnight before being assayed for IFN- $\gamma$ or IL-4 production. (A) Induction of IFN- $\gamma$ positive cells in the spleen. (B) Induction of IFN- $\gamma$ positive cells in lymph node cells. (C) Induction of IL-4 positive cells in the spleen. Spleen cells from Group 4 (HEL + CT) induced the highest amount of IL-4 positive cells. Low levels of IL-4 positive cells were obtained from Group 5 (GM1-bp + HEL). (D) Induction of IL-4 positive cells in the lymph nodes. 

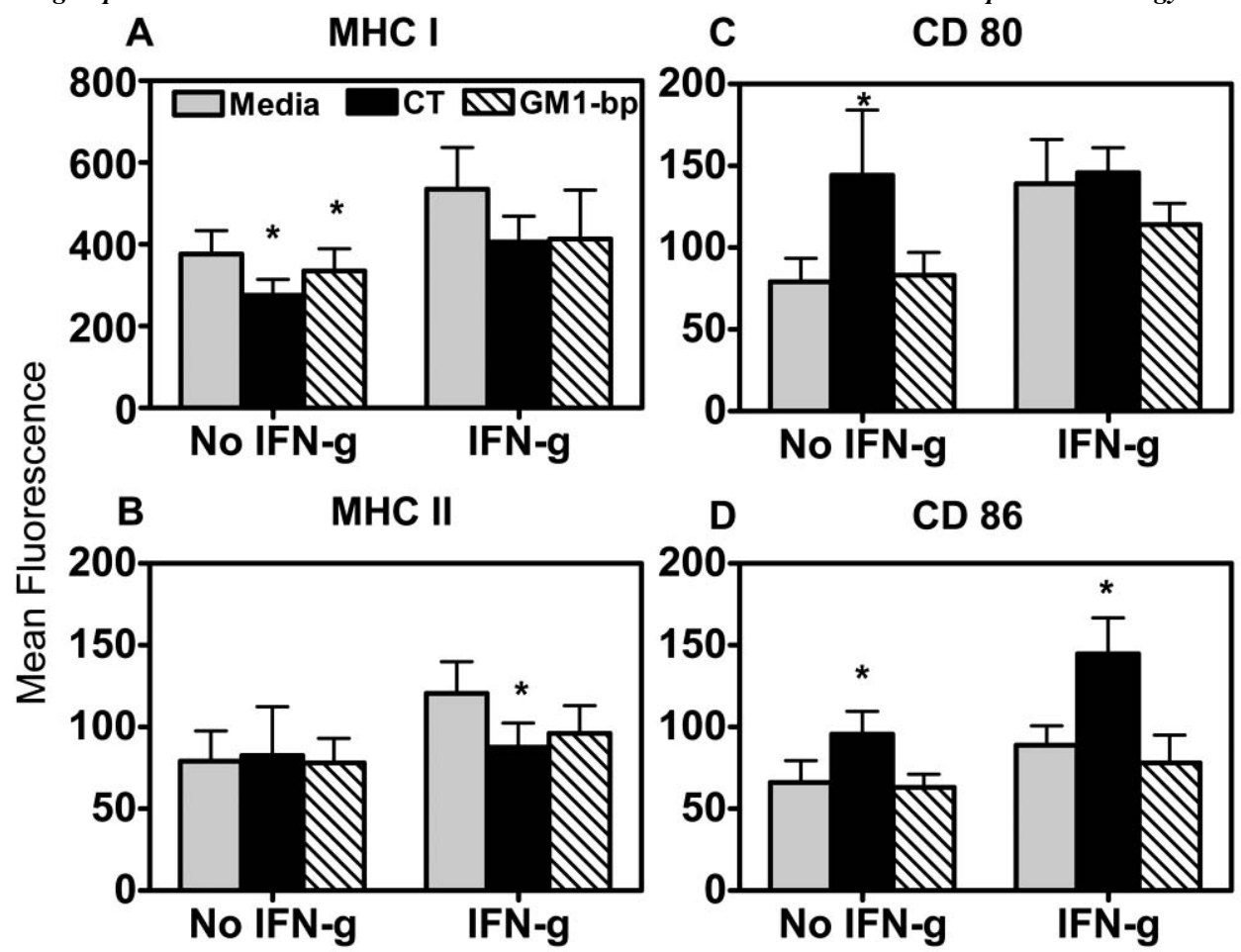

Fig. (4). Expression of cell surface markers on primary murine bone marrow-derived macrophages. Murine bone marrow-derived macrophages were either stimulated or not stimulated with IFN- $\gamma$ and cultured in media (gray bars), or in media containing $1 \mu \mathrm{g}$ CT (black bars), or with $1 \mu \mathrm{g}$ GM1-bp (hatched bars). Cells were stained for cell surface marker expression of MHC class I (A), MHC class II (B), CD80 $(\mathbf{C})$ and CD86 (D) molecules and analyzed by flow cytometry. A representative experiment is shown. * represents p $\leq 0.03$ compared to cells grown in media alone.

utilized JAWS II cells, a dendritic cell-like cell line. As described above for macrophages, JAWS II cells were either not stimulated or stimulated with IFN- $\gamma$ and then treated with either CT or GM1-bp and then analyzed for changes in the expression of cell surface markers by flow cytometry (Fig. 5). The data are expressed as the percent increase in geometric mean fluorescence compared to the respective unstimulated or IFN- $\gamma$ stimulated JAWS II cells. Both CT and GM1-bp had very slight effect on the expression of MHC class I and class II molecules on unstimulated cells (Fig. 5A). In contrast to the down regulation of MHC class II molecules induced by CT on stimulated macrophages (Fig. 4B), there was an up regulation $(25 \%$ increase in the geometric mean fluorescence) of MHC class II molecules on the surface of stimulated JAWS II cells treated with CT (Fig. 5A). GM1-bp did not affect the expression of either MHC class I or class II molecules (Fig. 6A). Both GM1-bp and CT induced an increase (7-8\%) in the surface expression of CD80 molecules on unstimulated cells (Fig. 5B). In IFN- $\gamma$ stimulated cells, only GM1-bp caused a further increase $(15 \%)$ in the levels of CD80 molecules (Fig. 5B). GM1- bp and $\mathrm{CT}$ also induced the upregulation of CD86 molecules on unstimulated (Fig. 5B) dendritic cells, although the increase with GM1-bp (37\%) was more pronounced with the unstimulated cells. Further stimulation with IFN- $\gamma$ caused a decrease in the expression of CD86 molecules. Overall, in the dendritic cells, GM1-bp increased the expression of the co-stimulatory markers compared to macrophages.

\section{DISCUSSION}

It is becoming increasingly clear that antigens by themselves are poor inducers of an immune response unless they are administered along with an adjuvant. Therefore, considerable attention and interest has been focused on developing and choosing the right type of adjuvant to generate the desired immune response. Several different adjuvants have been tested to induce a robust immune response to antigens administered through the mucosal route. The most potent adjuvants that induce strong mucosal immune responses are CT and LT. However in humans, these adjuvants cannot be co-administered along with the antigen through the oral route because of their extreme toxicity [25-26]. Both CT and LT bind with very high affinity to ganglioside GM1 through their pentameric B subunit, while the A subunit is responsible for the toxicity. Both CT and LT induce diarrhea [37] and use of LT through the intranasal route has been implicated as the causative agent of Bell's palsy [38]. Recombinant CTB devoid of contaminating A subunit has been shown to be highly immunogenic, however, it is not an ideal adjuvant for human use if it has to be administered through the oral route. Although, the toxic effects of CT and LT are not observed if they are delivered through the transcutaneous route $[27,28$, 39]. LT has been used as a skin patch in humans at the site of intramuscular injection of influenza vaccine and proven to be safe and highly successful in inducing immune responses to the antigen [39].

In this study, we utilized three of the 15-mer GM1-bp described by Matsubara et al. [29] to determine if these peptides can act as adjuvants to potentiate immune responses to a co-administered antigen applied on the surface of the skin. Montaner et al. identified an additional 45 GM1-bp using phage-displayed libraries of random peptides [30]. By 


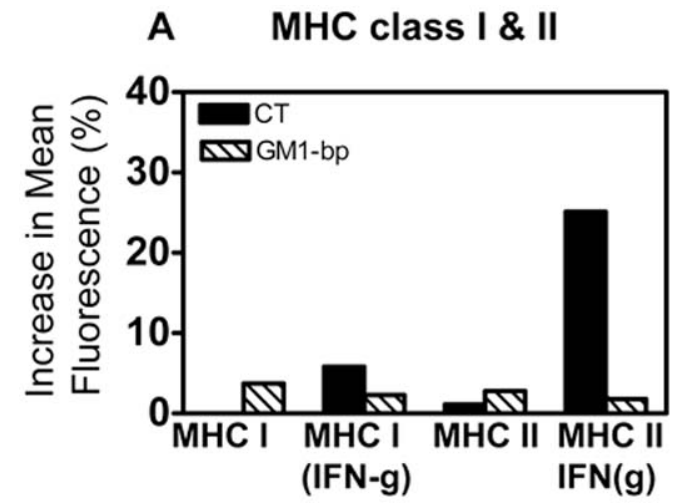

\section{B $\quad$ CD $80 \&$ CD 86}

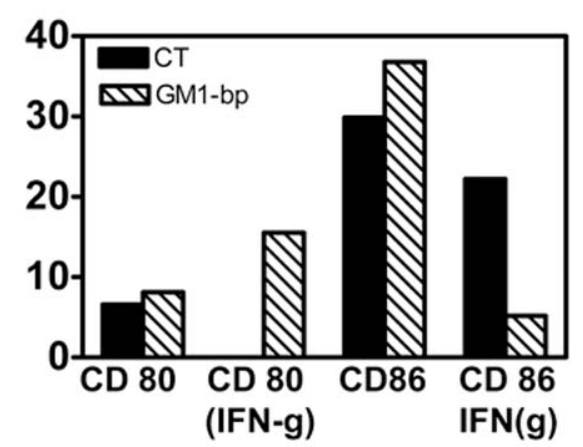

Fig. (5). Expression of cell surface markers on JAWS II dendritic cells. JAWS II cells were either stimulated or not stimulated with IFN- $\gamma$ and cultured in media, CT or GM-1 bp and stained as mentioned in Fig. (4) legend above. The data are expressed as \% increase in geometric mean fluorescence.

chemically coupling two of the GM-1 binding peptides to antigens, Montaner et al., demonstrated that by intranasal administration of the complex, mucosal as well as systemic antibodies could be generated in mice. However, the efficiency of the complex was dictated by the composition and structure of the GM1-bp and the antigen.

One immediate question of interest is whether these peptides potentiate immune responses to a co-administered antigen in a manner similar to CTB or LTB. By specifically binding ganglioside GM1, these peptides permit the study of the GM1 adjuvant properties without the additional sideeffects of CT [40]. Additionally, these peptides provided a tool to determine whether GM1 binding alone was sufficient to promote or limit the adjuvant activities of CT.

The present study differs from Montaner's study in two major aspects; (i) GM1-bp are not chemically coupled to the antigen and (ii) the route of administration is transcutaneous. Our data indicates that GM1 binding alone is sufficient to induce an immune response to HEL, the co-administered antigen. Like CT, GM1-bp when used as an adjuvant induced HEL-specific IgG antibodies, although the titers were about 16-fold lower when GM1-bp was used as the adjuvant. Similarly, the cytokine responses to HEL were much lower when GMI-bp was used as the adjuvant when compared to CT. However, extremely high GM1-bp specific $\mathrm{T}$ cell proliferative responses were induced in the lymph nodes.

Cong et al. [41] showed that CT significantly increased the expression of CD86 without affecting CD80 expression on either IFN- $\gamma$ treated or untreated cells. Our results are slightly different from Cong et al. [41] in that we also see an increase in CD80 expression in the absence of IFN- $\gamma$. Whether the difference in results between the two studies arises as a result of using different strains of mice in the two studies is not known. The effects of CT and GM1-bp on the expression of surface molecules were different. CT significantly increased both co-stimulatory molecules, CD80 and CD86 on unstimulated murine bone marrow-derived macrophages. Upon stimulation with IFN- $\gamma$, there was no additional enhancement of CD80 molecules on IFN- $\gamma$ treated cells, whereas CD86 molecules were further significantly enhanced on IFN- $\gamma$ treated cells. On the other hand, GM1-bp did not affect the surface expression of either CD80 or CD86 molecules on stimulated or unstimulated bone marrowderived macrophages. The differential effects of CT and GM1-bp on co-stimulatory molecules suggest that these molecules could affect the immune signaling and cytokine release that would ultimately have an impact on the immune response.

Although, by binding ganglioside GM1 with GM1-bp, we obtained immunological responses, it was much weaker compared to CT. It is possible that other characteristics of B pentamer in binding to GM1 and cell signaling are required for unmitigated triggering of cell-signaling pathways that potentiate immune responses. One such characteristic is the ability of B pentamers to cluster GM1 by binding multiple GM1 moieties, which apparently leads to the coalescence of membrane microdomains known as lipid rafts, rich in GM1 and several important co-stimulatory molecules [42, 43]. The GM1-bps would be unlikely to display such effects when presented as uncoupled pentadecapeptides. This could be one reasons for the decreased immune responses observed. It may be possible to overcome this if the peptides are conjugated to resemble the $\mathrm{B}$ pentamer. It has also been demonstrated that $\mathrm{CT}$ can mobilize and induce the maturation of gut dendritic cells, which could also play a role in the induction of a stronger immune response [44].

In conclusion, our results demonstrate that binding GM1 alone is clearly sufficient to induce immune responses such as antigen-specific antibodies, $\mathrm{T}$ cell proliferation and cytokine release. Clearly, GM1 binding alone did not reproduce all of the adjuvant properties of $\mathrm{CT}$. Other cellular functions of CT may be responsible for its ability to induce robust immunological responses compared to GM1-bp. A major difference was in the induction of co-stimulatory molecules on macrophages and dendritic cells by CT compared to GM1-bp. An increase in the expression of costimulatory molecules can lead to increased antigen presentation and ultimately to a strong immunological response. Although, the exact mechanism of how GM1 binding results in the upregulation of co-stimulatory molecules is not clearly understood, it has been suggested that the ability to bind GM1 with high affinity is necessary but not sufficient for LTB to trip the signaling cascade that upregulates immune responses to co-administered antigen $[42,45]$. The above findings suggest that targeting GM1 on antigen presenting cells by GM1-bp should be exploited 
either by coupling or conjugating the peptides to strengthen its adjuvant activity in order to enhance the immune responses to the administered antigen.

\section{ACKNOWLEDGEMENTS}

We gratefully acknowledge the assistance of Ms. Elaine Morrison for performing all of the animal immunization and sera collection.

\section{DISCLAIMERS}

The views expressed in this article are those of the authors and do not reflect the official policy of the Department of the Army, the Department of Defense, or the U.S. government.

\section{REFERENCES}

[1] Glenn GM, Rao M, Matyas GR, Alving CR. Skin immunization made possible by cholera toxin. Nature 1998; 391: 851 .

[2] Scharton-Kersten T, Glenn GM, Vassel R, Yu J, Walwender D, Alving CR. Principles of transcutaneous immunization using cholera toxin as an adjuvant. Vaccine 1999; 17(2): S37.

[3] Hammond S, Guebre-Xabier M, Yu J, Glenn GM. Transcutaneous immunization: an emerging route of immunization and potent immunostimulation strategy. Crit Rev Ther Drug Carrier Sys 2001; 18(5): 503-26.

[4] Pye D, Vandenberg KL, Dyer SL, et al. Selection of an adjuvant for vaccination with the malaria antigen MSA-2. Vaccine 1997; 15(9): 1017-23.

[5] Rao M, Matyas GR, Vancott TC, Birx DL, Alving CR. Immunostimulatory $\mathrm{CpG}$ motifs induce CTL responses to HIV type I oligomeric gp140 envelope protein. Immunol Cell Biol 2004; 82(5): 523-30.

[6] Richards RL, Rao M, Vancott TC, Matyas GR, Birx DL, Alving CR. Liposome-stabilized oil-in-water emulsions as adjuvants: increased emulsion stability promotes induction of cytotoxic $\mathrm{T}$ lymphocytes against an HIV envelope antigen. Immunol Cell Biol 2004; 82(5): 531-8.

[7] Matyas GR, Friedlander AM, Glenn GM, Little S, Yu J, Alving, CR. Needle-free skin patch vaccination method for anthrax. Infect Immun 2004; 72(2): 1181-83.

[8] Peachman KK, Rao M, Alving CR, et al. Correlation between lethal toxin-neutralizing antibody titers and protection from intranasal challenge with Bacillus anthracis Ames strain spores in mice after transcutaneous immunization with recombinant anthrax protective antigen. Infect Immun 2006; 74(1): 794-7.

[9] Vogt A, Mahé B, Costagliola D, et al. Transcutaneous antiinfluenza vaccination promotes both CD4 and CD8 T cell immune responses in humans. J Immunol 2008; 180(3): 1482-9.

[10] Mkrtichyan M, Ghochikyan A, Movsesyan $\mathrm{N}$, et al. Immunostimulant adjuvant patch enhances humoral and cellular immune responses to DNA immunization. DNA Cell Biol 2008; 27(1): 19-24.

[11] Spangler BD. Structure and function of cholera toxin and the related Escherichia coli heat-labile enterotoxin. Microbiol Rev 1992; 56(4): 622-47.

[12] Zhang RG, Scott DL, Westbrook ML, et al. The three-dimensional crystal structure of cholera toxin. J Mol Biol 1995; 251(4): 563-73.

[13] Freytag LC, Clements JD. Bacterial toxins as mucosal adjuvants. Curr Top Microbiol Immunol 1999; 236: 215-36.

[14] Dickinson BL, Clements JD. Dissociation of Escherichia coli heatlabile enterotoxin adjuvanticity from ADP ribosyltransferase activity. Infect Immun 1995; 63(5): 1617-23.

[15] Cheng E, Cardenas-Freytag L, Clements JD. The role of cAMP in mucosal adjuvanticity of Escherichia coli heat-labile enterotoxin (LT). Vaccine 1999; 18(1-2): 38-49.

[16] Pizza M, Giuliani MM, Fontana MR, et al. Mucosal vaccines: non toxic derivatives of LT and CT as mucosal adjuvants. Vaccine 2001; 19(17-19): 2534-41.

[17] Nashar TO, Betteridge ZE, Mitchell RN. Evidence for a role of ganglioside GM1 in antigen presentation: binding enhances presentation of Escherichia coli enterotoxin B subunit (EtxB) to CD4(+) T cells. Int Immunol 2001; 13(4): 541-51.
[18] Holmgren J, Czerkinsky C, Lycke N, Svennerholm AM. Strategies for the induction of immune responses at mucosal surfaces making use of cholera toxin B subunit as immunogen, carrier, and adjuvant. Am J Trop Med Hyg 1994; 50: 42-54.

[19] Guidry JJ, Cardenas L, Cheng E, Clements JD. Role of receptor binding in toxicity, immunogenicity, and adjuvanticity of Escherichia coli heat-labile enterotoxin. Infect Immun 1997; 65(12): 4943-50.

[20] de Haan L, Hirst TR. Cholera toxin: a paradigm for multifunctional engagement of cellular mechanisms. Mol Membr Biol 2004; 21(2): 77-92.

[21] Richards CM, Aman AT, Hirst TR, Hill TJ, Williams NA. Protective mucosal immunity to ocular herpes simplex virus type 1 infection in mice by using Escherichia coli heat-labile enterotoxin B subunit as an adjuvant. J Virol 2001; 75(4): 1664-71.

[22] de Haan L, Verweij WR, Holtrop M, et al. Nasal or intramuscular immunization of mice with influenza subunit antigen and the B subunit of Escherichia coli heat-labile toxin induces IgA- or IgGmediated protective mucosal immunity. Vaccine 2001; 19(20-22): 2898-907.

[23] Rask C, Fredriksson M, Lindblad M, Czerkinsky C, Holmgren J. Mucosal and systemic antibody responses after peroral or intranasal immunization: effects of conjugation to enterotoxin B subunits and/or of co-administration with free toxin as adjuvant. APMIS 2000; 108(3): 178-86.

[24] George-Chandy A, Eriksson K, Lebens M, Nordstrom I, Schon E, Holmgren J. Cholera toxin B subunit as a carrier molecule promotes antigen presentation and increases CD40 and CD86 expression on antigen-presenting cells. Infect Immun 2001; 69(9): 5716-25.

[25] Frech SA, Dupont HL, Bourgeois AL, et al. Use of a patch containing heat-labile toxin from Escherichia coli against travellers' diarrhoea: a phase II, randomised, double-blind, placebocontrolled field trial. Lancet 2008; 371(9629): 2019-25.

[26] McKenzie R, Bourgeois AL, Frech SA, et al. Transcutaneous immunization with the heat-labile toxin (LT) of enterotoxigenic Escherichia coli (ETEC): protective efficacy in a double-blind, placebo-controlled challenge study. Vaccine 2007; 25(18): 368491.

[27] Fujihashi K, Koga T, van Ginkel FW, Hagiwara Y, McGhee JR. A dilemma for mucosal vaccination: efficacy versus toxicity using enterotoxin-based adjuvants. Vaccine 2002; 20(19-20): 2431-8.

[28] Mutsch M, Zhou W, Rhodes P, et al. Use of the inactivated intranasal influenza vaccine and the risk of Bell's palsy in Switzerland. N Engl J Med 2004; 350(9): 896-903.

[29] Matsubara T, Ishikawa D, Taki T, Okahata Y, Sato T. Selection of ganglioside GM1-binding peptides by using a phage library. FEBS Lett 1999; 465(2): 253-56.

[30] Montaner AD, De Nichilo A, Elias F, et al. Ganglioside GM1binding peptides as adjuvants of antigens inoculated by the intranasal route. Vaccine 2006; 24(11): 1889-96.

[31] Scharton-Kersten T, Yu J, Vassell R, O'Hagan D, Alving CR, Glenn GM. Transcutaneous immunization with bacterial ADPribosylating exotoxins, subuits, and unrelated adjuvants. Infect Immun 2000; 68(9): 5306-13.

[32] Glenn GM, Scharton-Kersten T, Vassell R, Matyas GR, Alving CR. Transcutaneous immunization with bacterial ADP-ribosylating exotoxins as antigens and adjuvants. Infect Immun 1999; 67(3): $1100-6$.

[33] Rao M, Matyas GR, Vancott TC, Birx DL, Alving CR. Immunostimulatory $\mathrm{CpG}$ motifs induce CTL responses to HIV type I oligomeric gp140 envelope protein. Immunol Cell Biol 2004; 82(5): 523-30

[34] Rao M, Bray M, Alving CR, Jahrling P, Matyas GR. Induction of immune responses in mice and monkeys to Ebola virus after immunization with liposome-encapsulated irradiated Ebola virus: protection in mice requires CD4(+) T cells. J Virol 2002; 76(18): 9176-85.

[35] Rao M, Rothwell SW, Wassef NM, Pagano RE, Alving CR. Visualization of peptides derived from lipsome-encapsulated proteins in the trans-Golgi area of macrophages. Immunol Lett 1997; 59(2): 99-105.

[36] Gattoni A, Parlato A, Vangieri B, Bresciani M, Derna R Interferon-gamma: biologic functions and HCV therapy (type I/II) (1 of 2 parts). Clin Ter 2006; 157(4): 377-86. 
[37] Ganguly NK, Kaur T. Mechanism of action of cholera toxin \& other toxins. Indian J Med Res 1996; 104: 28-37.

[38] Couch RB. Nasal vaccination, Escherichia coli enterotoxin, and Bell's palsy. N Engl J Med 2004; 350(9):860-1.

[39] Frech SA, Kenney RT, Spyr CA, et al. Improved immune responses to influenza vaccination in the elderly using an immunostimulant patch. Vaccine 2005; 23(7): 946-50.

[40] Spangler BD. Structure and function of cholera toxin and the related Escherichia coli heat-labile enterotoxin. Microbiol Rev 1992; 56(4): 622-47.

[41] Cong Y, Weaver CT, Elson CO. The mucosal adjuvanticity of Cholera toxin involves enhancement of costimulatory activity by selective up-regulation of B7.2 Expression. J Immunol 1997; 159(11): 5301-08.
[42] de Haan L, Feil IK, Verweij WR, Agsteribbe E, Wilschut J. Mutational analysis of the role of ADP-ribosylation activity and GM1-binding activity in the adjuvant properties of the Escherichia coli heat-labile enterotoxin towards intranasally administered keyhole limpet hemocyanin. Eur J Immunol 1998; 28(4): 1243-50.

[43] Aman AT, Fraser S, Merritt EA, et al. A mutant cholera toxin B subunit that binds GM1- ganglioside but lacks immunomodulatory or toxic activity. Proc Natl Acad Sci USA 2001; 98(15): 8536-41.

[44] Anjuère $\mathrm{F}$, Luci $\mathrm{C}$, Lebens $\mathrm{M}$, et al. In vivo adjuvant-induced mobilization and maturation of gut dendritic cells after oral administration of cholera toxin. J Immunol 2004; 173(8): 5103-11.

[45] Fraser SA, de Haan L, Hearn AR, et al. Mutant Escherichia coli heat-labile toxin B subunit that separates toxoid-mediated signaling and immunomodulatory action from trafficking and delivery functions. Infect Immun 2003; 71(3): 1527-37.

(C) Peachman et al.; Licensee Bentham Open.

This is an open access article licensed under the terms of the Creative Commons Attribution Non-Commercial License (http://creativecommons.org/licenses/by$\mathrm{nc} / 3.0 /$ ) which permits unrestricted, non-commercial use, distribution and reproduction in any medium, provided the work is properly cited. 